\title{
Noninvasive Helicobacter pylori testing was as effective as endoscopy for managing dyspepsia
}

\author{
McColl KE, Murray LS, Gillen D, et al. Randomised trial of endoscopy with testing for Helicobacter pylori compared with \\ non-invasive H pylori testing alone in the management of dyspepsia. BMJ 2002;324:999-1002.

\section{QUESTION: In patients with upper gastrointestinal symptoms presenting for investigation of dyspepsia, is treatment based on a urea breath test for Helicobacter pylori alone as effective as endoscopy and urea breath testing?}

\section{Design}

Randomised \{allocation concealed*\}†, unblinded,* controlled trial with 1 year of follow up.

\section{Setting}

A gastroenterology clinic in Glasgow, UK.

\section{Patients}

708 patients (mean age 37 y, 53\% men) who were referred by their general practitioners for investigation of upper gastrointestinal symptoms. Exclusion criteria were age $>55$ years, nonsteroidal anti-inflammatory drugs, or sinister symptoms. Follow up was $83 \%$.

NHS Executive

Research and

Development

Technology Assessment

Programme.

For correspondence:

Dr K McColl, Western

Infirmary, Glasgow,

$U K$

K.E.L.McColl@clinmed.

gla.ac.uk

Abstract and

commentary published

in ACP Journal Club
Patients were allocated to endoscopy plus the noninvasive ${ }^{14} \mathrm{C}$-urea breath test $(\mathrm{n}=352)$ or the breath test alone $(\mathrm{n}=356)$ for determination of $H$ pylori status. Patients were informed of their status after the test, and patients with positive results were prescribed a 7 day course of $H$ pylori eradication treatment with omeprazole, $20 \mathrm{mg}$ twice daily; clarithromycin, $250 \mathrm{mg} 3$ times daily; and amoxicillin, 500 $\mathrm{mg}$ (or metronidazole, $400 \mathrm{mg}$ ) 3 times daily.

\section{Intervention}

Noninvasive ${ }^{14} \mathrm{C}$-urea breath test $v$ endoscopy plus breath test for dyspepsia at 1 year $\ddagger$

\begin{tabular}{llll} 
Outcome & $\begin{array}{l}\text { Breath test } \\
\text { (baseline) }\end{array}$ & $\begin{array}{l}\text { Endoscopy plus } \\
\text { breath test (baseline) }\end{array}$ & $\begin{array}{l}\text { Difference in mean } \\
\text { change from baseline } \\
(95 \% \mathrm{Cl})\end{array}$ \\
$\begin{array}{c}\text { Glasgow Dyspepsia } \\
\text { Severity Score }\end{array}$ & $5.6(10.2)$ & $5.4(10.2)$ & $0.2(-0.7$ to 0.5$)$ \\
\hline
\end{tabular}

\section{Main outcome measures}

Change from baseline on the Glasgow Dyspepsia Severity Score (GDSS). Secondary outcomes were use of medical resources, patient assessment of the procedures, and safety.

\section{Main results}

Analysis was by intention to treat. At 1 year, the mean change from baseline on the GDSS was similar between groups $(\mathrm{p}=0.69)$ (table). The study had $90 \%$ power to detect a difference in mean change on the GDSS of 1.03 and 1.41 between the groups that were positive and negative for $H$ pylori, respectively. The mean reduction in GDSS was $46 \%$ in the endoscopy group and $45 \%$ in the breath test alone group. Groups did not differ for resolution of dyspepsia $(14 \% v 11 \%, \mathrm{p}=0.25)$. More patients who received the breath test alone were referred for further endoscopy than were those who received the breath test and endoscopy $(8.2 \% v 1.7 \%, \mathrm{p}<0.001)$. Groups did not differ for further nonendoscopic investigations.

\section{Conclusion}

In patients with upper gastrointestinal symptoms presenting for investigation of dyspepsia, a urea breath test for Helicobacter pylori was as effective as endoscopy plus breath test for managing dyspepsia.

*See glossary.

†Information provided by author.

\section{COMMENTARY}

Patients with dyspeptic symptoms should be managed with 2 goals in mind: early detection of malignant disease and cost-effective relief of symptoms. Patients $<55$ years of age without "alarm features" (eg, weight loss, dysphagia, and anaemia) are at very low risk of malignancy and do not require endoscopic investigation. The question of management then turns on the relative costs and effectiveness of endoscopy, noninvasive tests, and eradication of $H$ pylor $i$ and empiric acid suppression. ${ }^{1}$

The trials by McColl and Chiba and their colleagues provide important information for physicians managing patients presenting with uninvestigated dyspepsia. The study by McColl $e t$ al adds to 2 previous studies ${ }^{2-3}$ that confirm the cost effectiveness of a secondary care based $H$ pylor $i$ test and treat service compared with endoscopy based management. All 3 trials of test and treat compared with endoscopy based management showed equivalent effectiveness, but costs were reduced because fewer patients had endoscopy. The trial by McColl $e$ al showed a rate of endoscopy in the year of follow up in the test and treat group of only $8 \%$, whereas Heaney ${ }^{2}$ and Lassen ${ }^{3}$ showed rates nearer 30\%. Patients positive for $H$ pylor $i$ in both groups of the trial by McColl $e t$ al received eradication treatment. Thus, any differences caused by the eradication treatment itself were abolished. The trial can therefore be considered to address the question, "Is the cost of endoscopy warranted by the effect on symptoms, quality of life, and patient satisfaction of having the investigation?" The answer is "no".

The trial by Chiba et al (CADET- $H p$ ) takes the McColl et al trial 2 steps further. Firstly, patient recruitment and the intervention took place in a primary care setting. Secondly, test and treat was compared with acid suppression alone. In contrast to the trial by McColl $e t a l$, CADET- $H p$ was designed to examine the effect of eradication treatment on dyspeptic symptoms, and found a substantial improvement in the proportion of patients with dyspeptic symptoms at the end of the trial. However, the difference in costs was small and not statistically significant.

The reason for the difference in effects and costs between CADET- $H p$ and McColl $e$ al lies in the use of eradication treatment for $H p y l o r i$. In CADET- $H p$ the control group patients did not receive eradication treatment and were therefore at risk of recurrent peptic ulcers that had healed initially with omeprazole Continued on next page 


\title{
Helicobacter pylori eradication improved dyspepsia symptoms
}

\author{
Chiba N, Veldhuyzen van Zanten SJ, Sinclair P, et al. Treating Helicobacter pylori infection in primary care patients with \\ uninvestigated dyspepsia: the Canadian adult dyspepsia empiric treatment-Helicobacter pylori positive (CADET-Hp) \\ randomised controlled trial. BMJ 2002;324:1012-6.
}

\section{QUESTION: In patients with dyspepsia and a positive test result for Helicobacter pylori, is an $H$ pylori eradication strategy more effective than placebo for improving dyspepsia symptoms?}

\section{Design}

Randomised \{allocation concealed $*$ \} $\uparrow$, blinded (clinicians, patients, data collectors, outcome assessors, \{data analysts, and manuscript writers $\} \uparrow)$, * placebo controlled trial with 1 year of follow up.

\section{Setting}

36 family practices in Canada.

\section{Patients}

294 patients (mean age 49 y, 50\% men) who were $\geq 18$ years of age and had uninvestigated symptoms of dyspepsia for $\geq 3$ months. Dyspepsia was defined as a complex of epigastric pain including heartburn, acid regurgitation, excessive burping or belching, increased abdominal bloating, nausea, abnormal or slow digestion, or early satiety. All patients had to have positive test results for $H$ pylori on the Helisal rapid blood test and the ${ }^{13} \mathrm{C}$-urea breath test. Exclusion criteria included gastrooesophageal reflux disease, upper gastrointestinal investigation in the previous 6 months or $\geq 2$ times in the past 10 years, eradication therapy for $H$ pylori in the past 6 months, previous gastric surgery, ulcer disease or endoscopic oesophagitis, and irritable bowel syndrome. Follow up was $87 \%$.

\section{Intervention}

Patients were allocated to omeprazole, $20 \mathrm{mg}$; metronidazole, $500 \mathrm{mg}$; and clarithromycin, $250 \mathrm{mg}$ (eradication) $(\mathrm{n}=145)$ or omeprazole, $20 \mathrm{mg}$, and placebo metronidazole and placebo clarithromycin (placebo) $(\mathrm{n}=149)$ twice daily for 7 days.

\section{Main outcome measures}

Global overall severity (GOS) of dyspepsia symptoms assessed with a 7 point scale (1=no problem, $7=$ very severe problems). Treatment success was a score of 1 or 2. Secondary outcomes were proportion of asymptomatic patients and treatment success according to $H$ pylori status.

\section{Main results}

Analysis was by intention to treat, and an analysis with all evaluable patients was also done $(\mathrm{n}=267)$. Patients in the eradication group had greater treatment response than did those in the placebo group (table). More patients in the eradication group were completely asymptomatic (table). Treatment was more successful in patients in whom H pylori was eradicated than in those it was not $(54 \%$ v 39\%, $\mathrm{p}=0.02)$. Eradication treatment reduced societal costs, but the difference was not statistically significant (Cdn $\$ 53,95 \%$ CI -86 to 180 ).

\section{Conclusion}

In patients with dyspepsia and a positive test result for Helicobacter pylori, an $H$ pylori eradication strategy was more effective than placebo for improving dyspepsia symptoms.

*See glossary.

†Information provided by author.

H pylori eradication v placebo for uninvestigated dyspepsia at 1 year

\begin{tabular}{|c|c|c|c|c|}
\hline Outcomes & Eradication & Placebo & RBI (95\% Cl) & NNT (Cl) \\
\hline Treatment success & $50 \%$ & $36 \%$ & $37 \%(5$ to 80$)$ & 7 (4 to 63$)$ \\
\hline $\begin{array}{l}\text { Completely } \\
\text { asymptomatic }\end{array}$ & $28 \%$ & $15 \%$ & $92 \%$ (21 to 205$)$ & 8 (5 to 24$)$ \\
\hline
\end{tabular}

$\ddagger$ Abbreviations defined in glossary; RBI, NNT, and $\mathrm{Cl}$ calculated from data in article.

Source of funding:

Astra-Zeneca Canada Inc.

For correspondence: Dr N Chiba, Surrey GI Clinic/Research Guelph, Ontario, Canada. chiban@on.aibn.com

Abstract and commentary also published in ACP Journal Club

\section{COMMENTARY — continued from previous page}

Furthermore, patients with nonulcer dyspepsia may also benefit from $H$ pylori eradication. A Cochrane review of 9 placebo controlled trials of $H$ pylor $i$ eradication treatment in patients without peptic ulcers or oesophagitis at endoscopy found a number needed to treat of $15 .^{4}$

The CADET- $H p$ trial does not show conclusively that $H$ pylori test and treat is more cost effective in primary care than omeprazole alone, because it was only done in $\mathrm{H}$ pylori-positive patients. The cost effectiveness of this strategy needs to be tested by randomising patients with dyspepsia, both positive and negative for $\mathrm{H}$ pylori, before noninvasive testing for $\mathrm{H}$ pylori, to determine the effect of the management strategy on the whole group. It does, however, lend more support to the eradication of $H$ pylori in all patients known to be infected.

Brendan Delaney, MD, FRCP, MRCGP University of Birmingham Birmingham, $U K$

1 Delaney BC, Innes MA, Deeks J, et al. Initial management strategies for dyspepsia. Cochrane Database Syst Rev 2001;(3):CD001961.

2 Heaney A, Collins JS, Watson RG, et al. A prospective randomised trial of a"test and treat"policy versus endoscopy based management in young Helicobacter pylori positive patients with ulcer-like dyspepsia, referred to a hospital clinic. Gut 1999;45:186-90.

3 Lassen AT, Pedersen FM, Bytzer P, et al. Helicobacter pylori test-and-eradicate versus prompt endoscopy for management of dyspeptic patients: a randomised trial. Lancet $2000 \cdot 356: 455-60$

4 Moayyedi P, Soo S, Deeks J, et al. Eradication of Helicobacter pylori for non-ulcer dyspepsia. Cochrane Database Syst Rev 2001;(1):CD002096. 